\title{
Neighborhood Window Pixeling for Document Image Enhancement
}

\author{
Kirti S. Datir \\ P.G. Student \\ Dept. of Computer Engg, \\ Late G.N.Sapkal COE, Nashik
}

\author{
J. V. Shinde \\ Assistant Professor \\ Dept. of Computer Engg, \\ Late G.N.Sapkal COE, Nashik
}

\begin{abstract}
Many algorithms have been proposed for the document image binarization from past decades and still working on degraded document image is under process to generate more capable, noiseless and clear document image. Document image enhancement is very fashionable to improve old handwritten and machine printed documents. The proposed system enclose a new binarization technique that is image segmentation which contain neighborhood window pixel algorithm by using this technique detect text stroke edges and generate clear binarized image from the input image. Proposed system construct gray scale conversion using LC2G (Learning-based Color-to-Gray) used as pre-processing for document image enhancement. Image segmentation algorithm is used to generate the cleared binarized document image and single pixel artifacts removal algorithm is used to connect break edges due to the degradation.
\end{abstract}

\section{Keywords}

Document image binarization, Degraded document Image, Grayscale, LC2G.

\section{INTRODUCTION}

Historical documents are of nice interest to students in the social sciences and humanities. Theyare the memory of human cultures, their history, theirachievements, their lifestyles and their individual and socialbehaviors. Therefore, the preservation of those documentshas captured the eye of the many archives round theworld. The worth of those historical documents is immenselyimproved for consultation by the final public and forresearch functions through digitization that involves acquisition, processing and dissemination of information. Ahistorical document is exclusive, i.e., it doesn't have multiplecopies. It contains specific difficulties clogging access to itscontent, e.g. the presence of physical degradation caused byenvironmental situation, dust, dirt, etc. Such phenomenacontinue to hurt these precious objects, and so there'sa pressing would like for a technique of conserving associate degreed providing broader access to them. Digital archiving could be a normal way to meet this would like. Nevertheless, this task needs that archived pictures be increased so as to facilitate access to their valuable info. Image binarization is one amongst the preprocessing chains of document image sweetening needed before completely different tasks of study and recognition (i.e.OCR).Document image binarization, above all those based on thresholding strategy, aim at finding associate degree best threshold (gray-level) that separates the document image pixels into 2 categories, foreground and background.[1]

Document Image Binarization is performed within the preprocessing stage for document analysis and it aims to segment the foreground text from the document background.
A fast and correct document image binarization technique is important for the following document image process taskssuch as optical character recognition (OCR).

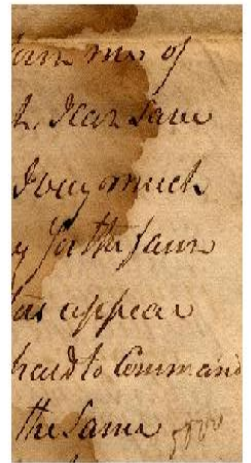

(a)

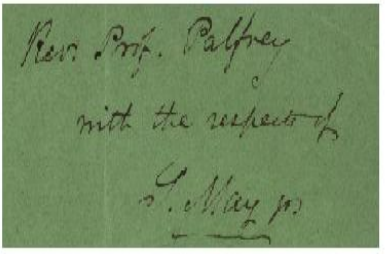

(c)

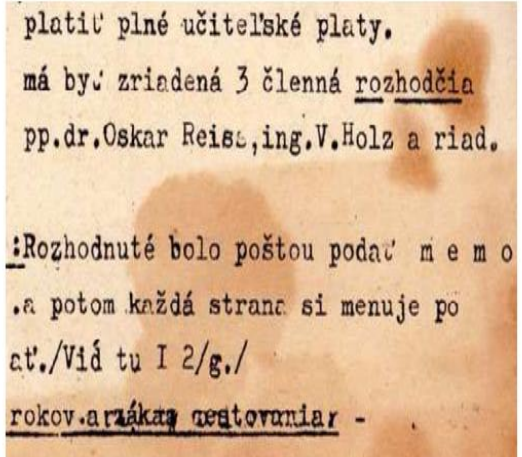

(b)

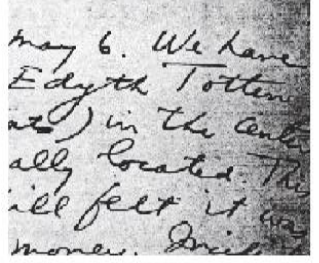

(d)
Fig 1: Degraded Document Images example taken from DIBCO series dataset.

Though document image binarization has been studied formany years, the thresholding of degraded document pictures is still an unresolved downside as a result of the high inter/intravariation between the text stroke and therefore the document background across completely different document pictures. As illustrated in Fig. 1, the handwritten text at intervals the degraded documents usually shows acertain amount of variation in terms of the stroke breadth, stroke brightness, stroke affiliation, and document background. In addition, historical documents are usually degraded by the bleed and wherever the ink of the other aspect seeps through to the front. Additionally, historical documents are usually degraded by differing kinds of imaging artifacts. These differing kinds of document degradations tend to induce the document thresholding error and build degraded document image binarization a big challenge to most progressive techniques. [2] 


\section{RELATED WORK}

\subsection{Grayscale Algorithm}

LC2G (Learning-based Color-to-Gray) color-to-gray conversion relies mainly on learning a linear filter (vector) from a predefined dataset of text pixels and background pixels. Once the filter is learned, it'll be applied to check a color document image to produce the gray-level document image during which the text class seems in similar intensity notwithstanding what the first color. [1]

The lightness method averages a huge quantity well-known and least familiar colors: $(\max (\mathrm{R}, \mathrm{G}, \mathrm{B})+\min (\mathrm{R}, \mathrm{G}, \mathrm{B})) / 2$. [3]

In MinAvearge method is simply calculate the average of 3 color that is average $=(\operatorname{Red}+$ Green + Blue $) / 3$. [3]

The luminosity technique is a more perplexing form of the normal strategy. It likewise midpoints the norms, yet it frames a weighted normal to form for human perception. More dedicated to green than different hues, so green is weighted generally nearly. The recipe for glow is $0.21 \mathrm{R}+0.72 \mathrm{G}+$ 0.07 B. [3]

\subsection{Binarization Algorithm}

Nib lack's algorithm [4] calculates a pixel-wise threshold by sliding a rectangular window over the gray level image. The working out of threshold is based on the local mean $m$ and the standard deviation $\mathrm{s}$ of all the pixels in the window. Advantage of Niblack is that it always identifies the text regions correctly as foreground but on the other hand tends to produce a big amount of binarization noise in non-text regions also.

Bernsen method [5] uses a user-provided contrast threshold. If the local contrast (max-min) is above or equal to the contrast threshold, the threshold is set at the local mid gray value (the mean of the smallest amount and highest grey values in the local window). If the local contrast is below the contrast threshold the neighborhood is considered to consist only of one group and the pixel is set to item or background depending on the value of the mid gray.

Adaptive Method [6] [7] an image using the threshold adaptive role, which calculates thresholds in regions of size block size surrounding each pixel (i.e. local neighborhoods). Each threshold value is the subjective mean of the local neighborhood minus an offset value.

Otsu's method [8] is used to automatically perform clusteringbased image thresholding or, the reduction of a gray level image to a binary image. The algorithm assumes that the image contains two classes of pixels following bi-modal histogram (foreground pixels and background pixels), it then calculates the optimum threshold separating the two classes so that their united stretch (intra-class variance) is minimal, or equivalently (because the sum of pair wise squared distances is constant), so that their inter-class variance is maximal.

\section{PROBLEM DEFINITION}

To overcome the drawbacks of existing approach a correct document image binarization technique is very important for the ensuing document image process tasks. Though document image binarization has been studied for variety of years, The thresholding of degraded document pictures continues to be associate degree unresolved problem attributable to the high intravariation among the text stroke and also the document backcloth across completely different document pictures thus, have a tendency to are introducing the tactic neighborhood window based thresholding that is employed to get the higher results.

\section{PROPOSED SYSTEM}

In pre-processing of document image binarization is translation of gray scale image from color image. Gray scale image is required for the elimination of noise, smoothing of background quality of degraded input document. Then on that gray scale image new-fangled image segmentation algorithm is applied to segment image into windows. In this method, each pixel in the image has it' own threshold by calculating the statistical information of the grayscale values of its neighborhood pixels. According to threshold rate gray scale image can binarize.Some post-processing algorithm is apply on the binarized image. Forefront pixels that are separate from other foreground pixels are clean out. Post Processing can also connect split edges due to degradation. So it can produce more clearly binarized image.

\subsection{Grayscale Conversion}

In pre-processing of document image binarization is translation of gray scale image from RGB image using LC2G (Learning-based Color-to-Gray).Gray scale image is very important for the removal of noise, smoothing of background texture of degraded input document.

\subsection{Image Segmentation}

Then on that gray scale image innovative image segmentation algorithm is apply to segment image into windows using neighborhood window based thresholding. In this method, each pixel in the image has its own threshold by calculating the statistical in sequence of the grayscale values of its region pixels. According to threshold value gray scale image can binarized.

\subsection{Single Pixel Artifacts Removal}

Single pixel artifacts removal algorithm is applied on the binarized image. Foreground pixels that is detach from other foreground pixels are filtered out. Single pixel artifacts removal can also connect break edges due to degradation. So it can clear weak edges from the binarized image and generate more cleared image. 


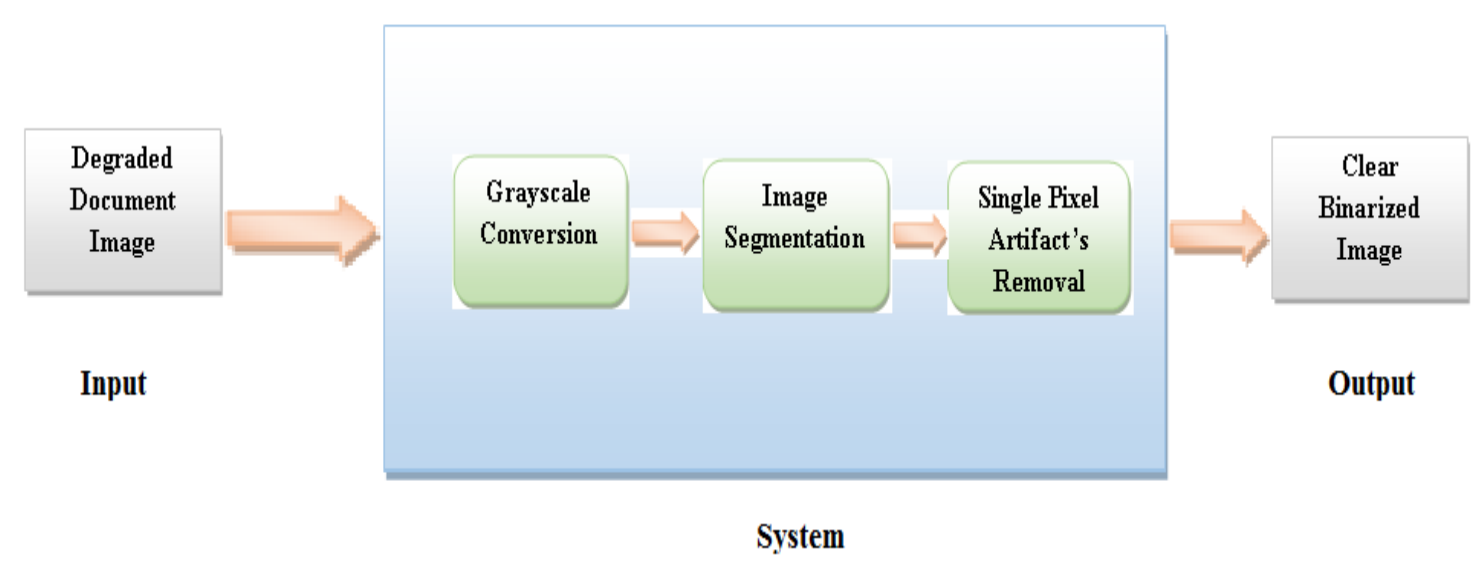

Fig 2: Proposed System Block Diagram

\section{IMPLEMENTATION DETAILS}

\subsection{Algorithm}

\subsubsection{Image Segmentation by calculating auto} thresholding

Steps:

1. Input:

1. Gray Scale Image (I)

2. Binarized image vector (v)

3. Window size $(\mathrm{ws})=40$

4. Segmented binarized image (sbz)

2. for each row $r 1$ to height-Ws

for each column c 1 to width-ws

$$
\begin{aligned}
& \text { Sum }=0 ; \\
& \text { Min=255; } \\
& \text { Max }=0 ;
\end{aligned}
$$

End for;

End for;

3. for each window

$$
\begin{aligned}
& \text { Int v=I.getpixel }(\mathrm{r} 1, \mathrm{c} 1) \text {; } \\
& \text { Sum=Sum }+\mathrm{v} ; \\
& \text { If }(\mathrm{v}<\text { Min }) \\
& \text { Min=v; } \\
& \text { If }(\mathrm{v}>\text { Max }) \\
& \text { Max=v; }
\end{aligned}
$$

End for.

Calculate Avg =Sum/ws;
Calculate auto threshold value th=Max-Min; Again For each window Int v=I.getpixel(r, c);

4. Check If (Avg - $v<$ th) Background; Else Foreground;

5. Return clear segmented binarized image sbz

Output: Binarized image sbz

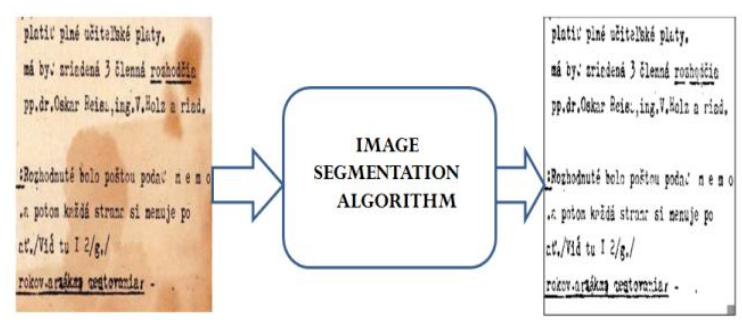

Fig 3: Output of Image Segmentation Algorithm

5.1.2 Single Pixel Artifact's Removal Algorithm Steps:

Input: Segmented binarized image Sbz;

Process:

1. for each Row ri to Sbz.height-3

2. for each Column cj to Sbz.width -3

3.Get its neighborhood pairs $(\mathrm{ri}+1, \mathrm{cj})$ and $(\mathrm{ri}+2, \mathrm{cj})$ and $(\mathrm{ri}, \mathrm{cj}+1)$ and (ri,cj+2)

4. If the pixels value black then

5. Assign the pixel (ri, cj) also black. 
6. End if

7. End for

8. Store the new binary result in Bz.

Output: Binarized image Bz.

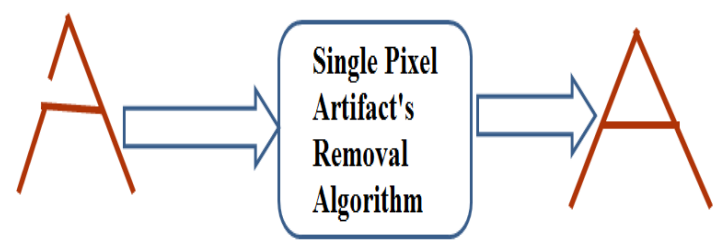

Fig 4: Output of Single pixel artifact's removal algorithm

\section{EXPERIMENTAL RESULTS}

\subsection{Experimental Setup}

The algorithm is implemented in .Net Framework 3.5 using c\#. To verify the result of the proposed system DIBCO, HDIBCO, FORTY-SIX (46) Historical Document Images this dataset are used and to check the performance of the system DIBCO13 evaluation metrics is used.

\subsection{Results}

Fig 5 shows the input image of the system i.e. degraded document and Fig 6 shows the results of the system. Here different binarization algorithm are implemented like Niblack method, Bernsen method, adaptive method, Otsu's method and the proposed method that is Image segmentation and the Single pixel artifacts removal algorithm which generate the more cleared binarized image. Input image is taken from DIBCO dataset for testing

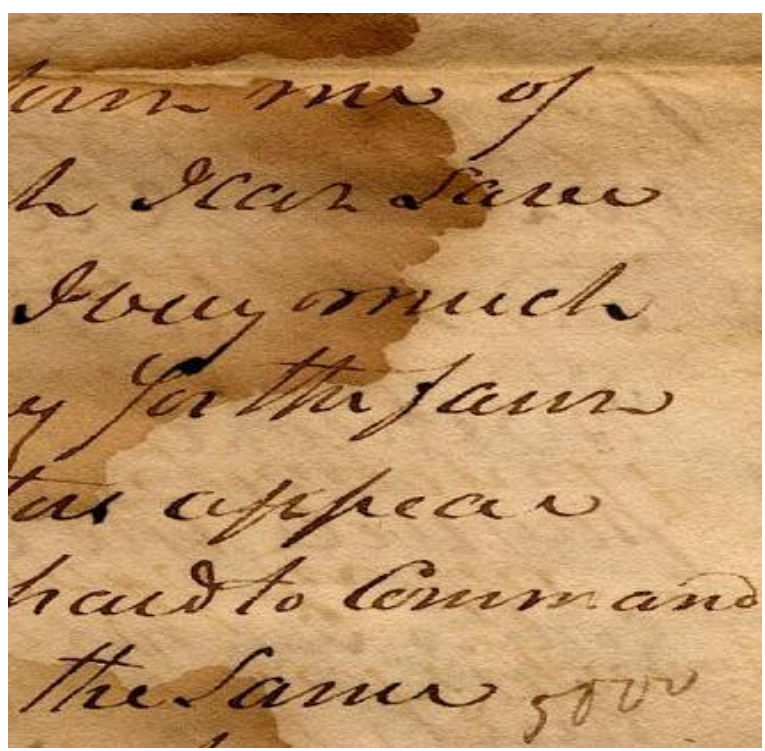

Fig 5: Input image taken from DIBCO dataset

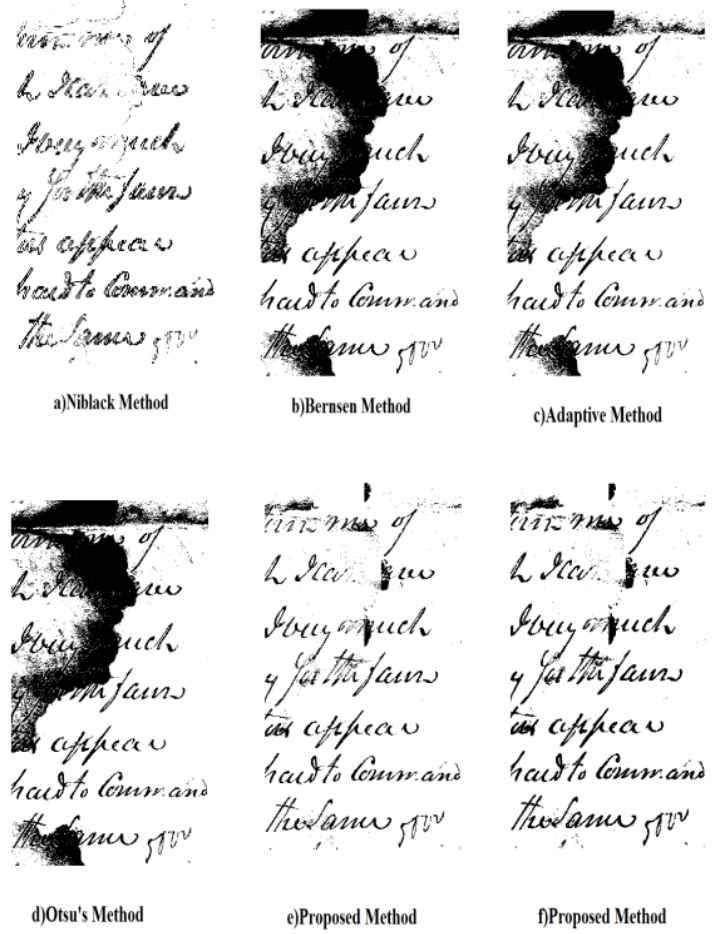

Fig 6: Result of different Binarization algorithm a) Niblack method b) Bernsen Method c) Adaptive Method d) Otsu's Method e) \& f) Proposed Method

\subsection{Result table}

Following table shows the evaluation parameter of the performance measure i.e. F Measure, PSNR, DRD

Table 1 . F-measure Evaluation of different Binarization Method using different Color-to-Gray techniques

\begin{tabular}{|l|l|l|l|l|l|}
\hline & $\begin{array}{l}\text { Niblac } \\
\mathbf{k}\end{array}$ & $\begin{array}{l}\text { Bernse } \\
\mathbf{n}\end{array}$ & $\begin{array}{l}\text { Adapti } \\
\text { ve }\end{array}$ & Otsu & $\begin{array}{l}\text { Propos } \\
\text { ed } \\
\text { Syste } \\
\text { m }\end{array}$ \\
\hline $\begin{array}{l}\text { MinAve } \\
\text { arge }\end{array}$ & $\begin{array}{l}43.562 \\
390\end{array}$ & $\begin{array}{l}41.757 \\
203\end{array}$ & $\begin{array}{l}44.140 \\
156\end{array}$ & $\begin{array}{l}47.104 \\
223\end{array}$ & $\begin{array}{l}74.974 \\
888\end{array}$ \\
\hline $\begin{array}{l}\text { Gimp- } \\
\text { Lightnes } \\
\text { s }\end{array}$ & $\mathrm{NaN}$ & 0.0795 & 0.3141 & 0.1505 & 0.6739 \\
71 & 87 & 78 & 37 \\
\hline $\begin{array}{l}\text { Gimp- } \\
\text { Lightnes } \\
\text { s }\end{array}$ & $\mathrm{NaN}$ & 0.1862 & 0.1623 & 0.1660 & 0.6332 \\
& 67 & 69 & 75 & 39 \\
\hline $\begin{array}{l}\text { Gimp- } \\
\text { Lumina } \\
\text { nce }\end{array}$ & $\mathrm{NaN}$ & 0.1862 & 0.1623 & 0.1660 & 0.6332 \\
& & 67 & 69 & 75 & 39 \\
\hline $\begin{array}{l}\text { Color2G } \\
\text { ray }\end{array}$ & $\mathrm{NaN}$ & 0.0945 & 0.2401 & 0.1032 & 4.4000 \\
\hline LC2G & $\mathrm{NaN}$ & 0.1757 & 0.1712 & 0.1448 & 0.4396 \\
& & 53 & 97 & 51 & 57 \\
\hline
\end{tabular}


Table 2. PSNR Evaluation of different Binarization Method using different Color-to-Gray techniques

\begin{tabular}{|c|c|c|c|c|c|}
\hline & $\begin{array}{l}\text { Niblac } \\
\mathbf{k}\end{array}$ & $\begin{array}{l}\text { Bernse } \\
\text { n }\end{array}$ & $\begin{array}{l}\text { Adapt } \\
\text { ive }\end{array}$ & Otsu & $\begin{array}{l}\text { Propos } \\
\text { ed } \\
\text { System }\end{array}$ \\
\hline $\begin{array}{l}\text { MinAvea } \\
\text { rge }\end{array}$ & $\begin{array}{l}11.484 \\
687\end{array}$ & $\begin{array}{l}6.2413 \\
62\end{array}$ & $\begin{array}{l}6.7219 \\
25\end{array}$ & $\begin{array}{l}7.3270 \\
84\end{array}$ & $\begin{array}{l}14.172 \\
361\end{array}$ \\
\hline $\begin{array}{l}\text { Gimp- } \\
\text { Lightnes } \\
\mathrm{s}\end{array}$ & $\begin{array}{l}15.302 \\
197\end{array}$ & $\begin{array}{l}3.0685 \\
29\end{array}$ & $\begin{array}{l}5.3404 \\
89\end{array}$ & $\begin{array}{l}5.8416 \\
95\end{array}$ & $\begin{array}{l}12.373 \\
106\end{array}$ \\
\hline $\begin{array}{l}\text { Gimp- } \\
\text { Luminan } \\
\text { ce }\end{array}$ & $\begin{array}{l}14.364 \\
233\end{array}$ & $\begin{array}{l}6.7670 \\
02\end{array}$ & $\begin{array}{l}6.1696 \\
28\end{array}$ & $\begin{array}{l}6.2678 \\
15\end{array}$ & $\begin{array}{l}12.100 \\
812\end{array}$ \\
\hline $\begin{array}{l}\text { Color2G } \\
\text { ray }\end{array}$ & $\begin{array}{l}37.067 \\
845\end{array}$ & $\begin{array}{l}3.8163 \\
09\end{array}$ & $\begin{array}{l}7.9280 \\
70\end{array}$ & $\begin{array}{l}4.1998 \\
52\end{array}$ & $\begin{array}{l}27.677 \\
193\end{array}$ \\
\hline LC2G & $\begin{array}{l}10.889 \\
077\end{array}$ & $\begin{array}{l}16.514 \\
201\end{array}$ & $\begin{array}{l}6.4024 \\
85\end{array}$ & $\begin{array}{l}5.6730 \\
61\end{array}$ & $\begin{array}{l}10.921 \\
748\end{array}$ \\
\hline
\end{tabular}

Table 3. DRD Evaluation of different Binarization Method using different Color-to-Gray techniques

\begin{tabular}{|c|c|c|c|c|c|}
\hline & $\begin{array}{l}\text { Niblac } \\
\mathbf{k}\end{array}$ & $\begin{array}{l}\text { Bernse } \\
\text { n }\end{array}$ & $\begin{array}{l}\text { Adapti } \\
\text { ve }\end{array}$ & Otsu & $\begin{array}{l}\text { Propos } \\
\text { ed } \\
\text { System }\end{array}$ \\
\hline $\begin{array}{l}\text { MinAv } \\
\text { earge }\end{array}$ & $\begin{array}{l}11.724 \\
724\end{array}$ & $\begin{array}{l}51.0696 \\
49\end{array}$ & $\begin{array}{l}45.557 \\
514\end{array}$ & $\begin{array}{l}39.388 \\
839\end{array}$ & $\begin{array}{l}5.5819 \\
35\end{array}$ \\
\hline $\begin{array}{l}\text { Gimp- } \\
\text { Lightn } \\
\text { ess }\end{array}$ & $\begin{array}{l}684.89 \\
1890\end{array}$ & $\begin{array}{l}11457.4 \\
38495\end{array}$ & $\begin{array}{l}6799.1 \\
5081\end{array}$ & $\begin{array}{l}6059.0 \\
92646\end{array}$ & $\begin{array}{l}1347.2 \\
99903\end{array}$ \\
\hline $\begin{array}{l}\text { Gimp- } \\
\text { Lumin } \\
\text { ance }\end{array}$ & $\begin{array}{l}850.61 \\
8554\end{array}$ & $\begin{array}{l}4896.96 \\
2445\end{array}$ & $\begin{array}{l}5618.8 \\
39129\end{array}$ & $\begin{array}{l}5493.2 \\
59444\end{array}$ & $\begin{array}{l}1434.6 \\
51326\end{array}$ \\
\hline $\begin{array}{l}\text { Color2 } \\
\text { Gray }\end{array}$ & $\begin{array}{l}1.9888 \\
69\end{array}$ & $\begin{array}{l}9660.21 \\
12\end{array}$ & $\begin{array}{l}3745.2 \\
052\end{array}$ & $\begin{array}{l}8843.1 \\
96965\end{array}$ & $\begin{array}{l}37.681 \\
471\end{array}$ \\
\hline LC2G & $\begin{array}{l}1896.0 \\
71708\end{array}$ & $\begin{array}{l}5190.97 \\
0074\end{array}$ & $\begin{array}{l}6299.5 \\
00469\end{array}$ & $\begin{array}{l}6299.5 \\
069\end{array}$ & $\begin{array}{l}1882.7 \\
01589\end{array}$ \\
\hline
\end{tabular}

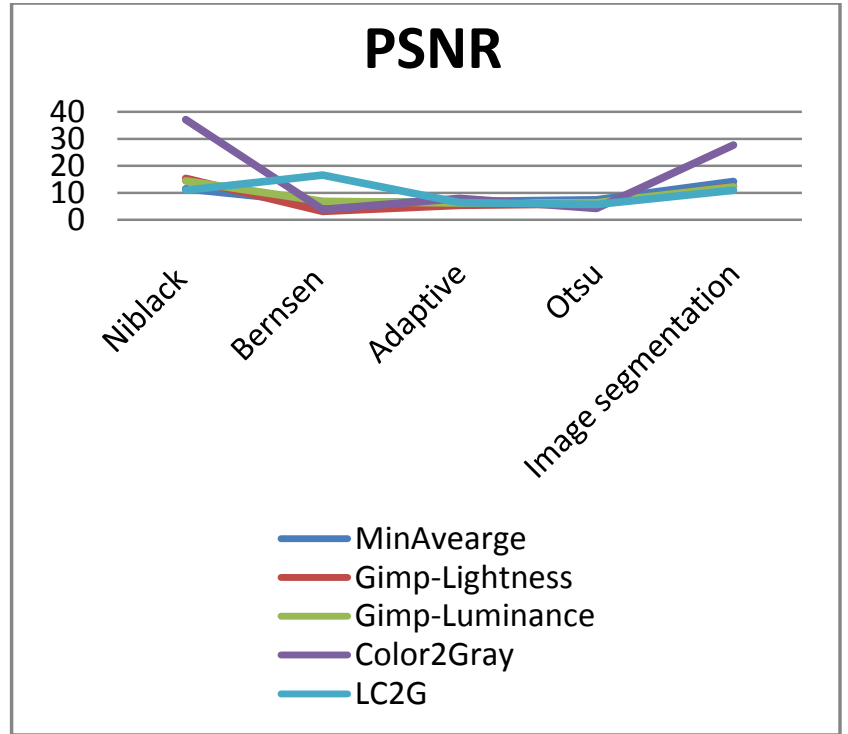

Fig 7. Binarization performance indicated by PSNR evaluation measure

\section{CONCLUSION}

In this paper an overview of Color2Gray conversion algorithms and binarization algorithms has been present and as a result of existing algorithm conclude that there does not exist a collective algorithm for segmenting all types of images so, image segmentation algorithm is proposed for degraded document image binarization. Its need fewer parameter setting which makes it easy and robust. The single pixel artifacts removal algorithm is valuable to produce clear record picture because of interfacing misty edges.

This paper reveals the hidden resolution for rising quality of degraded document image. The paper consists of novel approach for Image Segmentation that creates use of edge detection supported threshold segmentation during which pixel's threshold is calculated by mean of grayscale price. Thus the qualities of degraded image get improved. Additionally the projected system provides additional matter data with least noise. What is more, by victimization conception of post process, isolated foreground constituents area unit filtered dead set kind edge pixel set exactly. The performance obtained by projected system found higher than existing system with relevancy F-Measure, PSNR and DRD.

\section{FUTURE SCOPE}

As a future work proposed system can be extended by using parallel processing to reduce computational time. Also in binarization to minimize the loss of character information of degraded image, Optical Character Recognition (OCR) can be further implemented.

\section{ACKNOWLEDGMENTS}

The success and the final outcome of this project required a lot of advice and help from many people and I am extremely fortunate to have got this throughout the end of my project work. My deepest gratitude goes to my guide and PG coordinator Prof J .V. Shinde your help has been invaluable, as a Professor. Thank you for encouragement, and directing them my way. I will be in eternal debt to you and also thanks to all the staff members of the college.

\section{REFERENCES}

[1] RachidHedjam, Hossein Ziaei Nafchi, Margaret Kalacska and Mohamed Cheriet, Senior Member, 
"Influence of color-to-gray conversion on the performance of document image binarization: toward a novel optimization problem",IEEE-2015

[2] Bolan Su, Shijian Lu, and Chew Lim Tan, "Robust Document Image Binarization Technique for Degraded Document Images", Senior Member, IEEE-2013.

[3] R. Farrahi Moghaddam and M. Cheriet, "A multi-scale framework for adaptive binarization of degraded document images," Pattern Recognition, vol. 43, no. 6, pp. 2186-2198, Jun. 2010

[4] W. Niblack, an Introduction to Digital Image Processing. Birkeroed, Denmark: Strand berg Publishing Company, 1985.

[5] Bernsen local image thresholding by Jan Motl 18 Mar 2013

[6] B. Gatos, I. Pratikakis, and S. Perantonis, "Adaptive degraded document image binarization," Pattern Recognition, vol. 39(3), 317-327, 2006.

[7] Sauvola and M. Pietikainen, "Adaptive document image binarization,"Pattern Recognition, vol. 33, no. 2, pp. 225-236, Feb. 2000

[8] N. Otsu, "A threshold selection method from gray-level histograms," IEEE Trans. on Sys, Man and Cybernetics, vol. 9, 62-66, 1979.
[9] Hiping Zhu, Xi Xia, Qingrong Zhang Kamel Belloulata. "An Image Segmentation Algorithm in Image Processing Based on Threshold Segmentation",2011

[10] B. Gatos, K. Ntirogiannis, and I. Pratikakis, "ICDAR 2009 document image binarization contest (DIBCO 2009)," in Proc. Int. Conf. Document Anal. Recognit, Jul. 2009, pp. 1375-1382.

[11] I. Pratikakis, B. Gatos, and K. Ntirogiannis, "ICDAR 2011 document image binarization contest (DIBCO 2011)," in Proc. Int. Conf. Document Anal. Recognit, Sep. 2011, pp. 1506-1510.

[12] I. Pratikakis, B. Gatos, and K. Ntirogiannis, "H-DIBCO 2010 handwritten document image binarization competition," in Proc. Int. Conf. Frontiers Handwritten. Recognit. Nov. 2010, pp. 727-732

[13] M. Sezgin and B. Sankur, "Survey over image thresholding techniques and quantitative performance evaluation," J. Electron. Image., vol. 13, no. 1, pp. 146165, Jan. 2004

[14] G. Leedham, C. Yan, K. Takru, J. Hadi, N. Tan and L. Mian, "Comparison of some thresholding algorithms for text/background segmentation in difficult document images," in Proc. Int. Conf. Document Anal.Recognit. vol. 13. 2003, pp. 859-864. 